\title{
Strategic Harmonization of Training on Biosecurity for Laboratories in the ECOWAS Region ${ }^{\dagger}$
}

\author{
Abayomi Akinola Emmanuel 1, Denloye Abiodun Akinpelu 2, Diagne Rokhaya ${ }^{3}$, Diallo Sada ${ }^{4}$, \\ Ellis Maureen 5 , Faye Elhadji Abdourahmane ${ }^{6}$, Faye Ousmane ${ }^{6}$, Fofana Lorene ${ }^{\text {, }}$ \\ Kebe Khady ${ }^{8}$, Kouame Clarisse Elogne ${ }^{9}$, Manigart Olivier 10,11,*, Peyrefitte Christophe ${ }^{6}$, \\ Sakande Jean 7, Sall Amadou 6, Sarr Aicha Marceline 7, Sow Abdourahmane 10 \\ and Traore Tieble ${ }^{12}$
}

1 Nigerian Institute of Medical Research 6, Edmund crescent off Murtala Mohammed way, P.M.B. 2013 Yaba Lagos, Nigeria; profakinabayomi@gmail.com

2 Nigerian Biosafety Association, Suite 39, Shalom Plaza, Gudu District, FCT Abuja 900104, Nigeria; bio_denloye@yahoo.com

3 Senegalese Biosafety Association, Dakar 999066, Sénégal; Rokhayadiagne755@gmail.com

4 West African Network on Tuberculosis, Aids and Malaria (WANETAM), Arrondissement 4 Rue 2 D1 Pole urbain de Diamniado, BP 7325 Dakar, Senegal; souleymane.mboup@iressef.org

5 International Federation of Biosafety Associations (IFBA), 102-2460 Lancaster Road, Ottawa, ON K1B 4S5, Canada; m.ellis@internationalbiosafety.org

6 Institut Pasteur Dakar (IPD), Dakar 999066, Senegal; Abdourahmane.FAYE@pasteur.sn (F.E.A.); Ousmane.FAYE@pasteur.sn (F.O.); cpeyrefitte2000@yahoo.fr (P.C.); Amadou.SALL@pasteur.sn (S.A.)

7 Fondation Mérieux (FMx), 69002 Lyon, France; lorene.fofana@fondation-merieux.org (F.L.); jean.sakande@fondation-merieux.org (S.J.); aichamarceline.sarr@fondation-merieux.org (S.A.M.)

8 Association of Public Health Laboratories on behalf of Centre of Diseases Control (US CDC), Silver Spring, MD 20910, USA; didi_sn@yahoo.fr

9 Institut Pasteur de Côte d'Ivoire (IPCI), Abidjan 00225, Côte d'Ivoire; nzolecla@yahoo.fr

10 Department of Public Health and Research, West African Health Organization (WAHO), 01 BP 153 BoboDioulasso, Burkina Faso; asow@wahooas.org

11 Health Department, GFA Consulting Group GmbH, Eulenkrugstraße 82, 22359 Hamburg, Germany

12 World Health Organization (WHO), 1200 Geneva, Switzerland; traoret@who.int

* Correspondence: olivier.manigart@gfa-group.de

† Presented at the 5th African Conference on Emerging Infectious Diseases, Abuja, Nigeria, 7-9 August 2019.

Published: 22 July 2020

Abstract: Background: Good laboratory practices in terms of biosecurity and biosafety are essential for the protection of laboratory personnel, the populations and the environment. If not implemented, the risk of pathogen spreading from the laboratory is conceivable. In addition, in current African geopolitical context, the reliable practices such as the protection, control and tracking of valuable biological material will prevent their loss, theft, uncontrolled access and potential misuse. WAHO, with the support of $\mathrm{KfW}$ is implementing trainings of trainers on biosecurity in the ECOWAS region in a project called PROALAB. PROALAB team realized that many partners were aiming at implementing in parallel quite similar non internationally certified programs in the ECOWAS region. Therefore, PROALAB decided to organize a meeting of key stakeholders in order to pool efforts, avoid duplication, and harmonize strategies and procedures. Objective: Develop a harmonized strategy and harmonized procedures for the training of health professionals in biosecurity/biosafety and biohazard risk management in ECOWAS member countries to pass internationally certified biosafety and biosecurity examinations. Methods: Programs of each of the institutions were presented and discussed. A regional program on biosecurity/biosafety training was elaborated during group working and a regional program of certification of trainers was discussed and validated. A work plan and timeline were developed through group working. Results: In the ECOWAS region, some countries are more advanced in biosecurity training. Training is generally organized by national biosecurity associations with the 
support of the IFBA or other partners (WHO, FMx, PHE, etc.). Côte d'Ivoire, Nigeria and Mali seem more advanced and could be solicited to organize training for less-advanced countries. The IFBA certification covers five domains: (1) Biorisk management, (2) biosecurity, (3) biosafety cabinet, (4) biological waste management and (5) biocontainment facility. The technical working group decided consensually that basic training for biosecurity managers in the laboratories should cover the first two domains. More advanced experts advising governments should be trained in the other domains progressively. Progressive training could be built on the 3 levels Nigerian/Ivoirian system of "basicadvanced-consolidated (or expert)" system. Existing module from WHO, FMx, IPD, IPCI and other ECOWAS countries should be adapted to match the international certification needs. Practical training should also be organized in the laboratory by the same institutions that will be allowed to deliver a practical certificate on behalf of WAHO. Conclusion: With the extension of laboratory activities in the context of strengthening the surveillance programs in the ECOWAS region, more expertise on biosecurity is needed. With the support of national biosecurity associations, WAHO could play a role in harmonizing reinforcing training on biosecurity and legislation.

Keywords: biosecurity; biosafety; training; harmonized strategy; ECOWAS 